\title{
STUDY OF RENAL OSTEODYSTROPHY IN CHRONIC RENAL FAILURE
}

Nalina Thimmappa1, Giriraja Kanakapura Vrushabaih², Pula Laxmi Bindumathi³, Pooja Pillai ${ }^{4}$, Bhaskar Balasundaram ${ }^{5}$

${ }^{1}$ Associate Professor, Department of General Medicine, Sapthagiri Institute of Medical Sciences \& Research Centre, Bangalore.

2 Professor, Department of General Medicine, Sapthagiri Institute of Medical Sciences \& Research Centre, Bangalore.

3Professor \& HOD, Department of General Medicine, Sapthagiri Institute of Medical Sciences \& Research Centre, Bangalore.

${ }^{4}$ Assistant Professor, Department of General Medicine, Sapthagiri Institute of Medical Sciences \& Research Centre, Bangalore.

${ }_{5}^{5}$ Assistant Professor, Department of General Medicine, Sapthagiri Institute of Medical Sciences \& Research Centre, Bangalore.

\section{ABSTRACT}

\section{BACKGROUND}

The skeletal changes associated with the chronic renal failure were described even before 1855. Virchow in 1855 described the skeletal changes that he noticed in his study of chronic renal failure patients. Apart from its intrinsic clinical interest, renal osteodystrophy provides an opportunity to review various matters viz., (1) Mineral deficiencies in man, (2) The sites and mode of action of Vitamin-D, (3) Relation between crystal nucleation in bone and ionic concentration of Calcium and Phosphorus in plasma, (4) Control of parathyroid activity and secretion.

\section{METHODS}

Fifty cases of chronic kidney disease were included. Patients presenting with acute renal failure and senile osteoporosis (age $>65$ years) were excluded. Data will be collected by using pre-tested proforma meeting the objectives of the study. Purpose of the study will be carefully explained to the patients and consent will be taken. Relative investigations like (i) Serum calcium, (ii) Serum phosphorus, (iii) Serum alkaline phosphatase, (iv) Serum parathormone (if required), (v) Radiological - USG Abdomen, (vi) Plain Xray-Lumbar Spine, Hands and Wrists, Skull, Chest.

\section{CONCLUSION}

Clinically evident symptomatic bone disease was noticed in $80 \%$ of cases in the present study. Symptomatic skeletal involvement suggests osteomalacia rather than secondary hyperparathyroidism. Serum calcium X phosphorus product was well correlated with bone changes. Degree of renal impairment was well correlated with radiological bone changes.

\section{KEYWORDS}

Chronic Kidney Disease; Secondary Hyperparathyroidism; Osteomalacia; Renal Osteodystrophy.

HOW TO CITE THIS ARTICLE: Thimmappa N, Vrushabaih GK, Bindumathi PL, et al. Study of renal osteodystrophy in chronic renal failure. J. Evolution Med. Dent. Sci. 2016;5(20):1017-1021, DOI: 10.14260/jemds/2016/237

\section{INTRODUCTION}

The presence of renal bone disease in patients with chronic renal failure has been known for years. Virchow in 1855 described the skeletal changes that they noticed in his study of chronic renal failure patients. ${ }^{1}$

The Term Renal Osteodystrophy was used to include,

a) Osteitis fibrosa-high bone turnover (A reflection of secondary hyperparathyroidism).

b) Osteomalacia-low bone turnover, often but not always related to aluminium toxicity.

c) Adynamic Bone Disease (ABD)-low bone turnover.2,3

\section{SECONDARY HYPERPARATHYROIDISM}

Pathogenesis

\section{Definition}

Secondary hyperparathyroidism occurs when partial metabolic actions of the hormone lead to excessive parathyroid hormone production. It was a high bone turn-over disease.

Financial or Other, Competing Interest: None.

Submission 21-01-2016, Peer Review 19-02-2016,

Acceptance 25-02-2016, Published 09-03-2016.

Corresponding Author:

Nalina Thimmappa.

Doctors Quarters,

\#6, Sapthagiri Hospital,

Hesaragatta Road, Chikkabanavara,

Bangalore-560090.

E-mail: nalina2000@gmail.com

DOI: $10.14260 /$ jemds $/ 2016 / 237$

\section{RADIOGRAPHIC FEATURES OF SECONDARY}

\section{Hyperparathyroidism}

The most frequent and characteristic radiographic sign of renal hyperparathyroidism was the multiple small scalloping erosions found on the periosteal surfaces of digital phalanges. ${ }^{4}$ Sub-periosteal erosions of the phalanges identified with the use of fine grain radiographs of the hands are the single most sensitive radiographic sign of secondary hyperparathyroidism. ${ }^{5}$ Abnormalities on X-rays have been noted in $40-50 \%$ of patients with increased restorative surfaces on bone biopsy.5,6 Earliest lesions appear on the radial surface of middle phalanges of second or third digits of the dominant hand; first appear as slight irregularities near either the proximal or distal shoulder formed by the metaphysis. Eventually, erosion involves ulnar surface and other digits. ${ }^{7}$ The tufts of terminal phalanges of second and third digits show commonly resorption showing collapse of the soft tissue.

\section{OSTEOMALACIA}

\section{Morphology}

The main bone features include a low bone formation rate and a defect in bone mineralization, which was severe cases leads to osteomalacia.

\section{Radiographic Features of Osteomalacia}

The only pathognomonic feature of osteomalacia in adults was Looser's zones or pseudo fractures. 
These are straight, wide bands of radiolucency that abut the cortex and are usually perpendicular to the long axis of the bone. They may be bilateral and symmetric and may or may not be accompanied by a narrow area of sclerosis or a small poorly mineralized callus. ${ }^{7}$

\section{Adynamic Bone Disease (ABD)}

It was first described in uremic patients undergoing chronic dialysis. It was termed "Aplastic" or "Adynamic" bone disease. Because the main diagnostic criteria are abnormally low bone formation rate, the term Adynamic was preferred.8,9 It was reported that $60 \%$ of peritoneal dialysis patients and $36 \%$ of haemodialysis patients were found to have ABD. The real incidence of ABD was not known. The percentage varies from $10 \%$ to $48 \%$ among continuous ambulatory peritoneal dialysis patients and in $17 \%$ of haemodialysis patients. Thus, ABD was more common in continuous ambulatory peritoneal dialysis patients. ${ }^{9}$

Affected patients have a low bone formation rate without osteoid accumulation, which distinguishes this entity from osteomalacia. Ingestion of large doses of calcium carbonate or acetate as a phosphorus binder and excessive parathyroid suppression with calcitriol may also be the contributing factors in the development of ABD. ${ }^{9}$

\section{Clinical Features of ABD}

Clinical features of ABD are often asymptomatic without radiological abnormalities. Main clinical features include bone pain, fractures and decreased bone density.

\section{Extra Skeletal Calcifications}

Soft tissue calcifications of several different types are common in end-stage renal disease.

\section{Three Major Clinical Varieties have been noted viz.}

1. Calcification of medium sized arteries (Monkeberg's type)

2. Periarticular calcifications-three types:

a. Periarticular chondrocalcinosis,

b. Calcific periarthritis similar to dystrophic calcification, and

c. Tumoral calcinosis.

Periarticular calcification was seen in $7 \%$ to $45 \%$ of haemodialysis patients. Rubin, et al. noted that out of 37 patients, $44 \%$ had periarticular calcifications. ${ }^{10}$

3. Visceral calcifications involve heart, lungs and kidneys. Vascular calcifications may at first be detected as a ring or tube in the dorsalis paedis artery. ${ }^{11}$

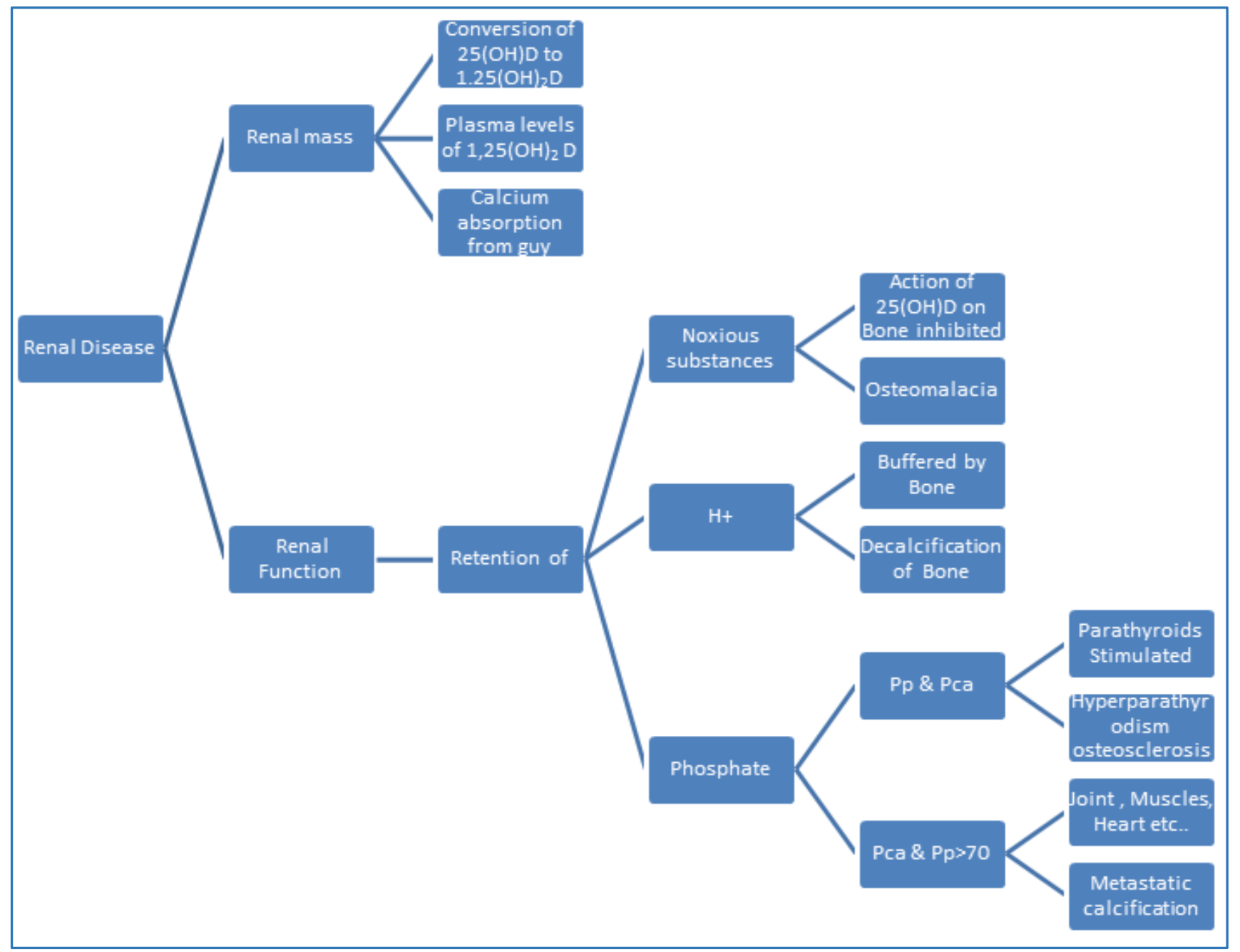

Fig. : Scheme of Mechanisms involved in aetiology of various disturbances of calcium and phosphate metabolism in chronic renal failure (De Wardener, 1972) 


\section{The Need for the Present Day}

a) The studies available in literature have been on population where the causative factors and the spectrum of renal osteodystrophy are at variance with our population. Available work in this field was scant in our country.

b) There has been a significant increase in the number of chronic renal failure cases due to an increase in the incidence of renal diseases leading on to chronic renal failure and due to availability of better diagnostic tools.

c) Improved treatment strategies, e.g. Dialysis have prolonged the survival of chronic renal failure patients, at the cost of increasing the morbidity in these patients. E.g. Renal osteodystrophy.

\section{METHODOLOGY}

\section{Source of Data}

Patients who are diagnosed to have chronic kidney disease, who fulfil inclusion and exclusion criteria.

\section{Method of Collection of Data}

Sample Size: 50 cases of chronic kidney disease meeting the inclusion criteria of present study.

Sampling Method: Simple random sampling.

\section{Inclusion Criteria}

Patients who are diagnosed to have chronic kidney disease according to National Kidney Foundation.

\section{Exclusion Criteria}

1. Patients presenting with acute renal failure.

2. Senile osteoporosis (Age $>65$ years).

Data will be collected by using pre-tested proforma meeting the objectives of the study. Purpose of the study will be carefully explained to the patients and consent will be taken. Institutional Ethical Committee Clearance will be taken.

\begin{tabular}{|c|c|c|c|}
\hline \multirow{2}{*}{$\begin{array}{c}\text { GFR } \\
(\mathbf{m L} / \mathbf{m i n})\end{array}$} & \multicolumn{2}{|c|}{ Bone Changes } & \multirow{2}{*}{ Total } \\
\cline { 2 - 3 } & Yes & No & \\
\hline$>90$ & 0 & 0 & 0 \\
\hline $60-90$ & 0 & 0 & 0 \\
\hline $30-60$ & $2(100 \%)$ & 0 & $2(4 \%)$ \\
\hline $15-30$ & $5(27.78 \%)$ & $13(72.22 \%)$ & $18(36 \%)$ \\
\hline$<15$ & $18(60 \%)$ & $12(40 \%)$ & $30(60 \%)$ \\
\hline Total & 23.1222 & 23.8778 & $49(100 \%)$ \\
\hline \multicolumn{4}{|c}{ Table 1 } \\
\hline
\end{tabular}

$\mathrm{P}$-value $=0.273$.

In the present study, GFR was calculated from creatinine clearance. Marked renal impairment was seen in 30 cases, GFR ( $<15 \mathrm{~mL} / \mathrm{min}$ ). Mean GFR was $10.5+4 \mathrm{~mL} / \mathrm{min} ; 60 \%$ of cases in the present study was marked renal impairment of GFR $<15$ $\mathrm{mL} / \mathrm{min}$. Bone changes was more common in CKD patients with GFR $<15 \mathrm{~mL} / \mathrm{min}(60 \%)$ compared to CKD patients with GFR $15-30 \mathrm{~mL} / \mathrm{min}$ (27.78\%), which was statistically not significant $(\mathrm{p}=0.273)$.

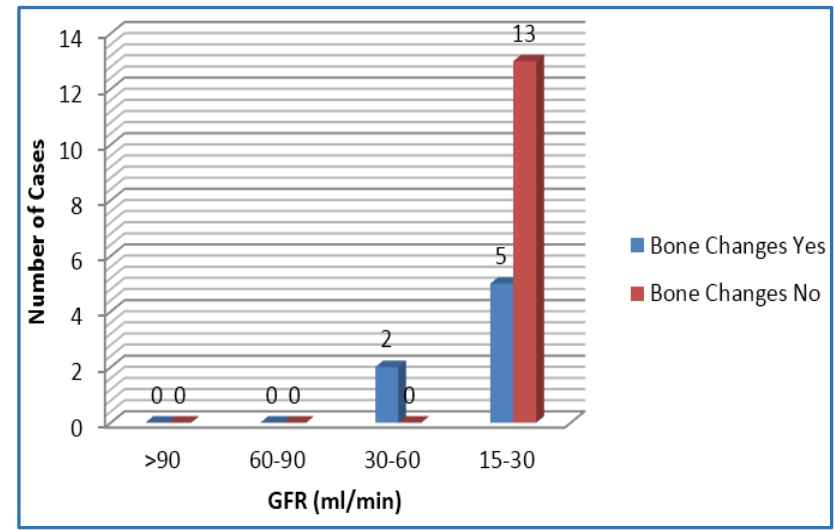

Fig. 1: GFR distributions in the present study of CKD Patients

\begin{tabular}{|c|c|c|c|}
\hline $\begin{array}{c}\text { S.ca } \\
\mathbf{m g}^{+} \mathbf{x} \mathbf{P h}^{+}\end{array}$ & \multicolumn{2}{|c|}{ Bone Changes } & Total \\
\hline & Yes & No & \\
\hline$<25$ & $1(100 \%)$ & 0 & $1(2 \%)$ \\
\hline $25-40$ & $11(39.28 \%)$ & $17(60.82 \%)$ & $28(56 \%)$ \\
\hline$>40$ & $13(61.9 \%)$ & $8(38.1 \%)$ & $49(100 \% 0$ \\
\hline Total & 22.9882 & 24.0108 & $49(100 \%)$ \\
\hline \multicolumn{4}{|c|}{ Table 2: Serum Calcium and Phosphorus Product } \\
Distribution in Present Study \\
\hline
\end{tabular}

$\mathrm{P}$-value $=0.275$.

In the present study, Serum calcium $X$ phosphorus product ranged between 23.08 and $53.04 \mathrm{mg}^{2} / \mathrm{dL}^{2}$ among 50 cases of CKD. Normal range was $25-40 \mathrm{mg}^{2} / \mathrm{dL}^{2}$. The mean was $38.49+5 \mathrm{mg}^{2} / \mathrm{dL}^{2} ; 28$ cases had normal S. $\mathrm{Ca}^{+} \mathrm{X} \mathrm{Ph}^{+}$values, 21 cases had increased value and 1 case had low value. Bone changes was seen more in CKD patients having serum calcium $\mathrm{X}$ phosphorus product $>40 \mathrm{mg}^{2} / \mathrm{dL}^{2}(61.9 \%)$ compared to $\mathrm{S}$. $\mathrm{ca}^{+} \mathrm{X} \mathrm{\textrm {ph } ^ { + }}$ product $25-40 \mathrm{mg}^{2} / \mathrm{dL}^{2}$ (39.28\%). Hence, bone changes increased as serum calcium $X$ phosphorus product increased, which was statistically not significant $(p=0.275)$.

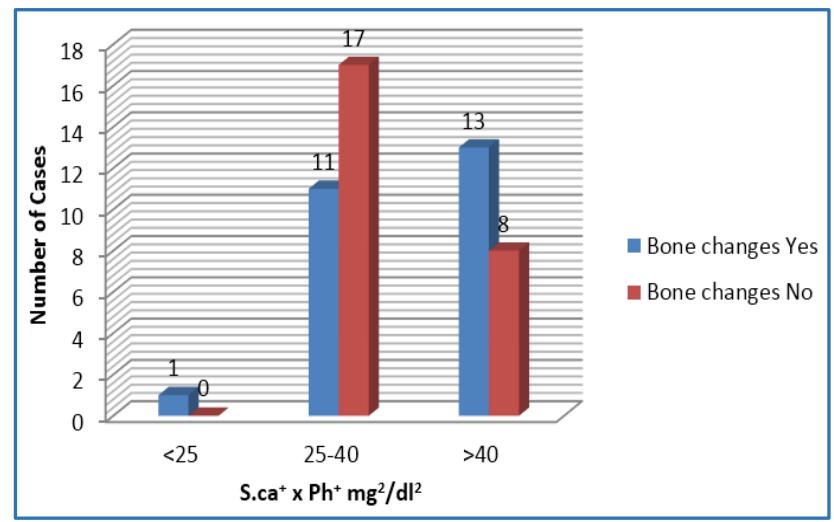

Fig. 2: Serum Calcium and Phosphorus Product Distribution in Present Study

Radiological Observations in the Present Study

Radiological survey included X-ray chest, dorsal spine, skull, long bones, small bones and vertebrae with pelvis. Decreased bone density was seen in $25(50 \%)$ cases, subperiosteal resorption in $3(6 \%)$ cases and fracture in $2(4 \%)$ cases. 


\begin{tabular}{|c|c|c|c|}
\hline USG & \multicolumn{2}{|c|}{ Bone Changes } & Total \\
\hline & Yes & No & \\
\hline Grade I & $6(28.57 \%)$ & $15(71.43 \%)$ & $21(42 \%)$ \\
\hline Grade II & $9(65.51 \%)$ & $10(34.49 \%)$ & $29(58 \%)$ \\
\hline Total & 24.0592 & 23.9408 & $49(100 \%)$ \\
\hline \multicolumn{4}{|c|}{ Table 3: Grades of Renal Disease by USG } \\
Abdomen in Present Study \\
\hline
\end{tabular}

p-value $=0.95$.

In the present study, CKD patients with Grade I medico renal disease had bone changes (28.55) compared to patients with Grade II medico renal disease (65.55). Thus, the incidence of bone changes increased with the increase in radiological severity of renal disease, which was statistically not significant $(\mathrm{p}=0.95)$.

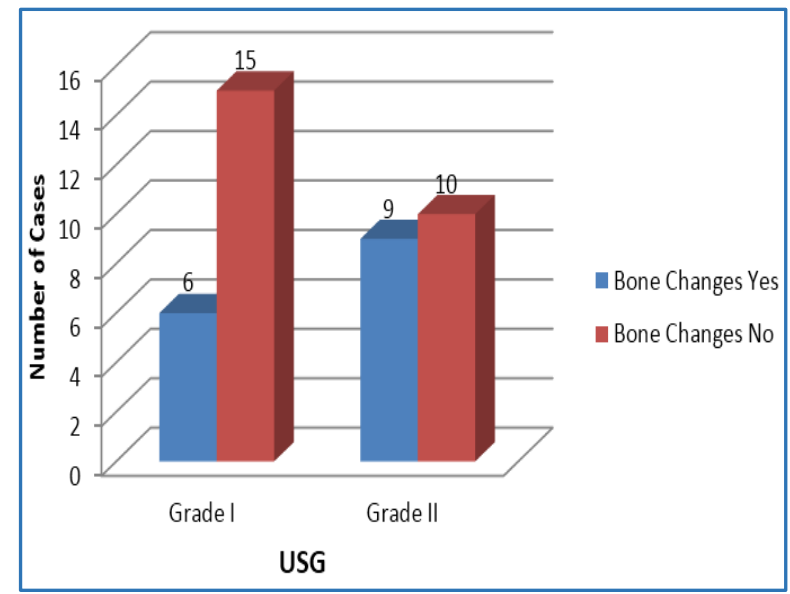

Fig. 3: Grades of Renal Disease by USG Abdomen in the Present Study

\section{RESULTS}

Fifty cases of CKD were studied. Male-to-female ratio was 2:3:1. Mean age was 44.82 years. Bone changes was more in patients with GFR $<15 \mathrm{~mL} / \mathrm{min}(60 \%)$ compared to the patients with GFR $15-30 \mathrm{~mL} / \mathrm{min}(27.78 \%)$. Bone changes was more in patients with S.ca*x ph* product $>40 \mathrm{mg}^{2} / \mathrm{dL}(61.9 \%)$ compared to $\mathrm{S} \mathrm{Ca}^{*} \mathrm{x} \mathrm{ph}^{*}$ product $25-40 \mathrm{mg}^{2} / \mathrm{dL}$ (39.28\%). Bone changes was more common in patients with Grade II medico renal disease (65.5\%) compared to Grade I medico renal disease $(28.5 \%)$.

\begin{tabular}{|c|c|c|c|}
\hline \multirow{2}{*}{ Sex } & \multicolumn{2}{|c|}{ Bone Changes } & \multirow{2}{*}{ Total } \\
\cline { 2 - 3 } & Yes & No & \\
\hline Male & $17(48.58 \%)$ & $18(51.42 \%)$ & $35(70 \%)$ \\
\hline Female & $8(53.33 \%)$ & $7(46.67 \%)$ & $15(30 \%)$ \\
\hline Total & 23.9809 & 24.0191 & 49 \\
\hline \multicolumn{3}{|c|}{ Table: Sex distribution in the Present } \\
Study of Chronic Kidney Disease Patients \\
\hline
\end{tabular}

In the present study, out of 50 cases studied 35 (70\%) were males and 15 (30\%) were females. The male-to-female ratio was 2.33:1. Bone changes was common in more number of female patients (53.33\%) when compared to males (48.58\%).

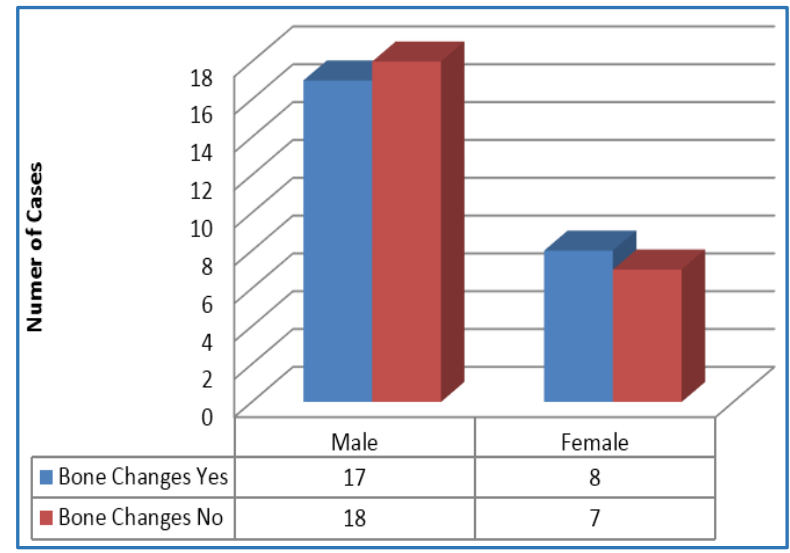

The present study comprises of 50 cases of chronic kidney disease admitted to K.R. Hospital, Mysore, during the period from November 2007 to August 2009.

\begin{tabular}{|c|c|c|c|}
\hline \multirow{2}{*}{$\begin{array}{l}\text { Age Group } \\
\text { (Years) }\end{array}$} & \multicolumn{2}{|c|}{ Bone Changes } & \multirow{2}{*}{ Total } \\
\hline & Yes & No & \\
\hline $21-30$ & $1(1.11 \%)$ & $8(90.89 \%)$ & $9(18 \%)$ \\
\hline $31-40$ & $5(38.46 \%)$ & $8(61.54 \%)$ & $13(26 \%)$ \\
\hline $41-50$ & $9(60 \%)$ & $6(40 \%)$ & $15(30 \%)$ \\
\hline $51-60$ & $6(75 \%)$ & $2(25 \%)$ & $8(16 \%)$ \\
\hline $61-70$ & $3(75 \%)$ & $1(25 \%)$ & $4(8 \%)$ \\
\hline $71-80$ & $1(100 \%)$ & 0 & $1(2 \%)$ \\
\hline Total & 21.5043 & 0 & 49 \\
\hline \multicolumn{4}{|c|}{$\begin{array}{l}\text { Age Distribution in the Present } \\
\text { Study of Chronic Kidney Disease }\end{array}$} \\
\hline
\end{tabular}

$\mathrm{p}$-value $=0.157$

In the present study, the age variation was from 23 years to 73 years. Mean age was 44.82 years. Maximum number of cases of CKD were in the age group of 30-60 years. Mean of bone changes was seen in more percentage of cases with CKD in 71-80 years range. This shows that as the age increases bone changes with CKD becomes more common, which was statistically not significant $(\mathrm{P}<0.157)$.

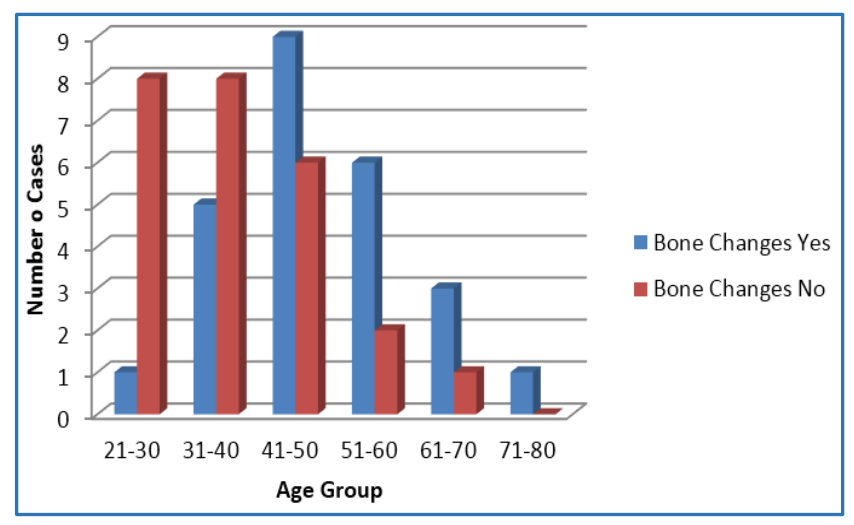

Age Distribution in the Present Study of Chronic Kidney disease

\section{DISCUSSION}

The present study, a study of renal osteodystrophy was carried out in 50 chronic kidney disease cases with marked impairment in renal function. 


\section{Symptoms}

The renal insufficiency was calculated from the creatinine clearance, marked renal impairment (GFR $<15 \mathrm{~mL} / \mathrm{min}$ ) was present in $60 \%$ of cases. Clinically evident bone disease was related more commonly with symptoms suggestive of osteomalacia rather than hyperparathyroidism in the present study.

\section{Radiological Abnormalities}

In the present study $50 \%$ showed various radiological changes, i.e. decreased bone density, fractures as evidence of osteomalacia and subperiosteal resorption of phalanges as evidences of secondary hyperparathyroidism.

\begin{tabular}{|c|c|c|c|c|c|c|}
\hline X-Ray Changes & Rizvi et al. & Batila et al. & Meena et al. & Gupta et al. & Sahoo et al. & Present Study \\
\hline Number of Cases & 67 & 50 & 32 & 40 & 100 & 50 \\
\hline $\begin{array}{c}\text { No bone changes } \\
\text { on X-ray }\end{array}$ & $19(28.36 \%)$ & $14(28 \%)$ & $17(53.12 \%)$ & $12(30 \%)$ & $60(60 \%)$ & $25(50 \%)$ \\
\hline Abnormal X-ray & $48(71.64 \%)$ & $36(72 \%)$ & $15(46.88 \%)$ & $28(70 \%)$ & $40(40 \%)$ & $25(50 \%)$ \\
\hline $\begin{array}{c}\text { a. Decreased bone } \\
\text { density }\end{array}$ & $37(55.22 \%)$ & $22(44 \%)$ & $4(12.5 \%)$ & $19(47.5 \%)$ & $32(32 \%)$ & $25(50 \%)$ \\
\hline $\begin{array}{c}\text { b. Increase bone } \\
\text { density }\end{array}$ & $11(16.41 \%)$ & - & $7(21.87 \%)$ & $7(17.5 \%)$ & $4(4 \%)$ & - \\
\hline $\begin{array}{c}\text { c. Subperiosteal } \\
\text { resorption }\end{array}$ & $17(25.37 \%)$ & $27(54.3 \%)$ & $8(25 \%)$ & $17(42.5 \%)$ & $36(36 \%)$ & $3(6 \%)$ \\
\hline $\begin{array}{c}\text { d. Skeletal } \\
\text { deformity }\end{array}$ & $22(38.3 \%)$ & - & $2(6.25 \%)$ & - & $8(8 \%)$ & $8(16 \%)$ \\
\hline $\begin{array}{c}\text { e. Metastatic } \\
\text { calcification }\end{array}$ & - & $1(2 \%)$ & $16(50 \%)$ & $4(10 \%)$ & - & - \\
\hline f. Cystic changes & $13(19.4 \%)$ & - & $1(3.12 \%)$ & - & $4(4 \%)$ & - \\
\hline \begin{tabular}{c} 
g. Fractures \\
\hline
\end{tabular} & $30(44.78 \%)$ & $1(2 \%)$ & - & - & $4(4 \%)$ & $2(4 \%)$ \\
\hline
\end{tabular}

Among 25 patients are with skeletal abnormalities.

a. $100 \%$ cases showed decreased bone density in the present study, which was comparable with Rizvi et al. and Batila et al.

b. Subperiosteal resorption was observed in $6 \%$ of cases in present study, $25 \%$ in Rizvi et al., $54 \%$ by Batila et al., $25 \%$ by Meena et al.

\section{Association between Serum Calcium and Phosphorus Product and Radiological \\ Skeletal Abnormalities}

Among 25 cases with radiological skeletal changes, $68 \%$ cases had increased serum calcium and phosphorus product and $32 \%$ had normal serum calcium and phosphorus product. Serum calcium $\mathrm{X}$ phosphorus product was more important predictor of bone abnormalities as per the present study.

\section{CONCLUSION}

Clinically evident symptomatic bone disease was noticed in $80 \%$ of cases in the present study. Symptomatic skeletal involvement suggests osteomalacia rather than secondary hyperparathyroidism. Serum calcium X phosphorus product was well correlated with bone changes. Degree of renal impairment was well correlated with radiological bone changes.

\section{REFERENCES}

1. Virchow R. Arch Path Anal 1855;8:103.

2. Liu SH, Chu HI. Studies of calcium and phosphorous metabolism with special reference to pathogenesis and effects of dihydrotachysterol (AT 10) and Iron. Baltimore:Medicine 1943;22(2):103-61.
3. Stanbury SW, Lumb GA. Metabolic studies of renal osteodystrophy: I. calcium, phosporous and nitrogen metabolism in rickets, osteomalacia and hyperparathyroidism complicating chronic uremia and the osteomalacia of the adult fanconi syndrome. Baltimore:Medicine 1962;41:1-34.

4. Dent CE, Harper CN, Philpot G. Treatment of renal glomerular osteodystrophy. Q J Med 1961;30:1-31.

5. Doyle FH. Radiological patterns of bone disease associated with renal glomerular failure in adults. $\mathrm{Br}$ Med Bull 1972;28(3):220-224.

6. Meema HE, Rabinovich S, Meema S. Improved radiological diagnosis of Azotemic osteodystrophy. Radiology 1972:102(1):1-10.

7. Parfitt AM. Clinical and radiographic manifestations of renal osteodystrophy. In: calcium metabolism in renal failure and nephrolithiasis, David OS, ed. New York: John Wiley and sons 1977;P-150-90.

8. Sherrard DJ, Ott S, Maloney N. Renal osteodystrophy: classification, cause and treatment. In: clinical disorders of bone and mineral metabolism, Frame B, Potts JT Jr, eds. Amsterdam: Excerpta medica:1983;P-254-9.

9. Hercz G, Pei Y, Greenwood C. Aplastic osteodystrophy without aluminium: the role of suppressed parathyroid function. Kidney Int 1993;44(4):860-6.

10. Bardin T, Vasseur M, de Vernejoal MC. Etude prospective de $L$ atteinte articular des maladies hemodialysis depuis plus de 10 ans. Rev rheum 1988;55:131-4.

11. Tatler GLV, Baillod RA, Varghese Z. Evolution of bone disease over 10 years in 135 patients with terminal renal failure. BMJ 1973;4(5888):315-319. 